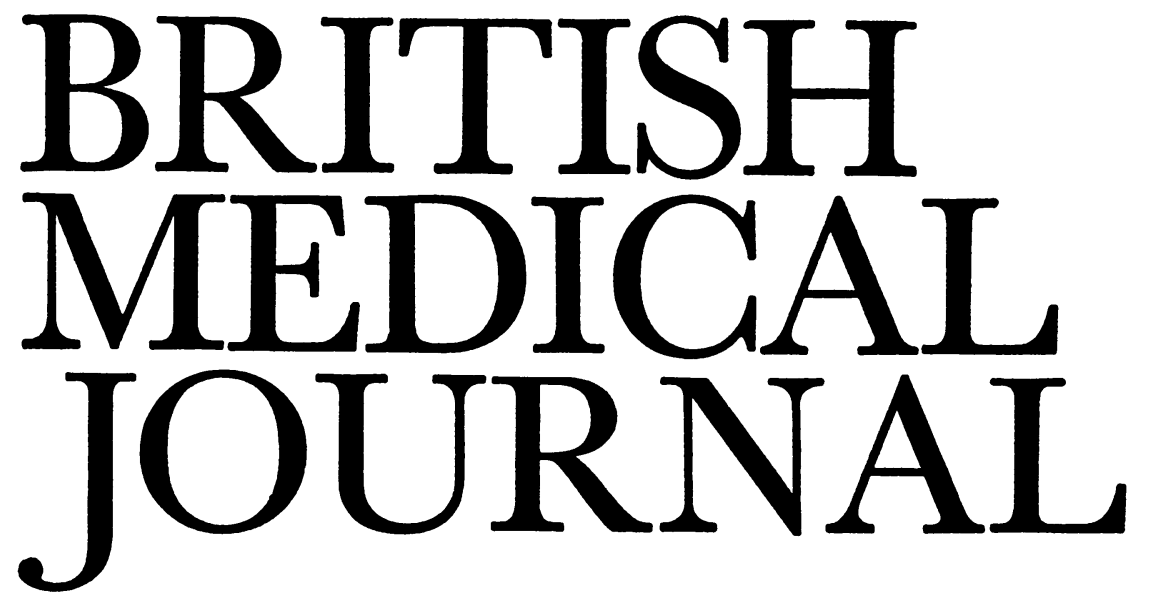

LONDON SATURDAY 12 MAY 1973

\title{
Much in Common
}

Events during the past year or so have highlighted some divisions of opinion among doctors. These disturbances partly reflect the profession's efforts to adjust to a changing and demanding society and the feeling too that the profession's structures are old-fashioned and need a shake up. Nevertheless, despite the accent on age differences and the demands of this or that group or specialty, the agendas of the B.M.A.'s fonthcoming craft and annual conferences, while bringing debateable questions into prominence, show that doctors of all kinds have much in common apart from their basic training. (The agendas of the A.R.M. and S.R.M. are published in this week's Supplement.)

With N.H.S. reorganization round the corner it will naturally figure prominently in all the meetings (the S.R.M. is devoted to the subject) and public health doctors-for whom it will bring a major change in life style-spent most of their recent conference discussing the impending changes. ${ }^{1}$ Education is another obvious common professional interest. A proposal from Warley before the Conference of Representatives of Local Medical Committees urges that all general practitioners admitted as principals after 1977 "must have completed a recognized course of vocational training," and Tower Hamlets will try to persuade the Representative Body that "there should be minimal standards of postgraduate education for all doctors providing general medical services. ..."The Newcastle region, blaming lack of communication between the various bodies responsible for postgraduate training as a major reason for the "staffing crises in many peripheral hospitals," asks the Conference of Hospital staffs to support an urgent review of postgraduate education.

If the agendas are a barometer of professional feeling, interest in the E.E.C. is low. This should be a subject of widespread professional interest but the implications of entry into the Common Market for training and standards in medicine seem not yet to have diffused through to the surgery or the ward. Perhaps by next year this will have changed, because progress towards free movement of doctors, though slow, is bound to have an impact on the profession in Britain. For the present doctors appear to regard another common professional interest, the General Medical Council, as sub judice, for the A.R.M. has attracted only a handful of motions on the subject and the two other conferences have none. In contrast, family planning is well represented on the agendas of both the L.M.C. Conference
- where the subject occupies nearly a quarter of it-and the A.R.M. Kent L.M.C. will launch the debate next week by condemning the Government's contraception policy as "instigating an historic, misguided and deplorable change in the social and moral values in this society." Gateshead is to follow by welcoming the inclusion of family planning work in the N.H.S. but it lays down some tough conditions. Indeed, many of the motions reflect concern about work load, pay, and the lack of consultation by the Government with the profession on this controversial topic.

The National Hospital Staffs Conference (N.H.S.C.) lacks any comments on family planning. This could be explained because the Government's plan will have its main impact on doctors outside the hospital service. But in any case the blanket nature of the hospital doctors' present contract makes it less easy than in general practice for staff to relate pay to any increase in workload. However, if the Central Committee for Hospital Medical Services achieves its aim of a reformed consultant contract ${ }^{2}$-and the H.J.S. Group Council is hard on its heels with a new draft contract for juniorsthen arbitrary additions to the workload by Government decree should be a thing of the past for hospital doctors. Perhaps surprisingly, in view of the critical correspondence there has been in the medical press about the new contract, there are only three motions about it from the regions, but the Chairman of the C.C.H.M.S., Dr. C. E. Astley, has put down a motion seeking reaffirmation of the conference's previous overwhelming support for his committee's proposals. ${ }^{3}$ The sceptical hospital doctor might argue that the presence of only three motions on such an important matter merely demonstrates the apathetic attitude of hospital staff towards their representative machinery. Yet the N.H.S.C. is celebrating only its second birthday-in contrast with L.M.C.'s 60 years of conferences-and it has a respectably-sized agenda covering a wide range of subjects, inoluding special risk insurance, study leave, residential accommodation, and distinction awards, which should amply fill its Saturday meeting.

Representing hospital doctors is not easy because of the diversity of interests among them, a difficulty which barely intrudes into general practice, and the motions about Chambers on the hospital conference agenda will give hospital staff a chance to debate the matter thoroughly. It should be seized because the outcome could be invaluable to the Representative Body when it discusses the Council's extensive report on Chambers "in principle" and the likely impact on the 
profession's representative machinery. ${ }^{4}$ Chambers will almost certainly be the paramount issue at Folkestone and representatives will have to indulge in some mental gymnastics in coping with its ramifications. But they should make their prime objective a united profession and an Association in which every group or interest knows that it can have a fair hearing. It is certainly ironic-and perhaps propheticthat while doctors argue vigorously over who best represents what in medicine the British Medical Students' Association has been busily pressing for more co-operation between all those training in the health services and has taken part in a recent 300-strong health students conference which called for a National Association of Health Students. Though their committee-hardened seniors might be tempted to dismiss the students' theme of unity as youthful idealism that would soon melt in the heat of day-to-day professional practice, the B.M.S.A. may well have sown a fertile seed. Fragmentation within the N.H.S. has hardly benefited patients and, idealism apart, the prospect of management taking a firmer hold on the N.H.S. after 1974 suggests that more coherent interprofessional co-operation-foreseen in the recent Hendry Report ${ }^{5}$ - would be a valuable and practicable aim. But doctors will first need to put their own house in order.

British Medical fournal Supplement, 1973, 1, 81.

2 British Medical fournal Supplement, 1972, 3, 39.

British Medical fournal Supplement, 1972, 3,60.

British Medical fournal Supplement, 1973,1,133.

Scortish Home and Health Department, The Organization of a Medical Advisory Structure, Edinburgh. H.M.S.O. 1973.

\section{Drug-induced Respiratory Disorders}

Drugs are readily blamed for a rash or an upset stomach but are rarely considered as a cause of cough and dyspnoea. In general they harm the lungs less often than some other organs. But in the lungs the danger can be greater partly because of their vital function and partly because the correct diagnosis may not even be suspected.

Adverse effects of drugs can be due to the known pharmacological actions of the drug, to an allergic mechanism, or to an idiosyncrasy in the patient. Drug-induced diseases of the respiratory system include central suppression of ventilation, bronchial asthma, inflammatory lesions in the lungs, and pulmonary vascular changes.

The best known and perhaps the most important respiratory complications of drug therapy are hypoventilation and abolition of the cough reflex due to depression of the medullary centres. Even a small dose of a barbiturate or other narcotic drug can have serious consequences in patients with severe airways obstruction and hypercarbia. Oxygen administered to such a patient at a concentration greater than about $30 \%$ may also suppress ventilation by abolishing the stimulus of hypoxia.

Bronchial asthma can be a specific pharmacological effect of a bronchoconstrictor agent, as may occur during the treatment of angina with a beta-receptor blocker-for example, propranolol. Asthma can also result from an allergic reaction (usually immediate or type I) to certain drugs, notably penicillin and other antibiotics. The mechanism of aspirin-induced asthma is obscure; it may be allergic in origin or a response to local neural reflexes. ${ }^{1}$ It should be mentioned here that aspirin can affect the respiratory system in three different ways: hyperventilation due to stimulation of the respiratory centre by acidosis; bronchial asthma; and pulmonary eosinophilia. ${ }^{2}$

Drug reactions within the lung itself may take the form of pulmonary eosinophilia, an allergic manifestation in which eosinophilic infiltrations of the lung are accompanied by fever, cough, sputum, dyspnoea, and crepitations. A variety of drugs may cause this but especially nitrofurantoin ${ }^{3}$ and sulphonamides $^{5}$ as well as aspirin. Some cases of polyarteritis and systemic lupus erythematosus, which can affect the lung along with other organs of the body, are thought to be drug-induced allergic reactions due to type III hypersensitivity. ${ }^{6}$

A desquamative alveolitis giving the clinical, radiographic, and physiological picture of pulmonary oedema followed later by fibrosis has been described in patients taking busulphan for chronic myeloid leukaemia.78 A similar condition may result from hexamethonium.9 The proliferation and shedding of granular pneumocytes in cases of busulphan lung has been attributed to physical or chemical irritation of the alveolar walls. This condition has aroused much interest in recent years and has served as a model for the careful study of drug-induced lung disease by serial prospective physiological measurements ${ }^{10} 11$ and by electron-microscopy. ${ }^{8}$ It should be stressed, however, that busulphan lung is a rare complication of a valuable treatment for a serious disease.

A drug may aggravate pre-existing lung disease, even one for which it has been prescribed. Thus antibiotics given for pneumonia may cause superinfection by fungi or other resistant organisms. Corticosteroids prescribed for a fibrosing alveolitis or asthma may provoke a pneumothorax ${ }^{12}$ or light up a quiescent tuberculous focus. And bronchodilator agents can actually worsen hypoxia by increasing the perfusion of poorly ventilated areas of lung. ${ }^{13}$

Pulmonary vascular disorders have recently been attributed to certain drugs. Contraceptive pills with a high oestrogen content can effect the pulmonary circulation in two ways-by inducing thrombo-embolism ${ }^{14}$ and by increasing the pulmonary capillary volume. ${ }^{15}$ An appetite-suppressant was recently suspected as the cause of an epidemic of "primary" pulmonary hypertension in Western Europe. ${ }^{16}$ Though this effect could not be reproduced in animal experiments, it has been shown that pulmonary hypertension can be induced by ingested matter, including "bush tea" in tropical countries and herbal preparations containing pyrrolizidine alkaloids. ${ }^{17} 18$

It remains to mention some pulmonary reactions to inhaled medicaments. These include lipoid pneumonia resulting from the aspiration of liquid paraffin or oily nose drops, iodism due to bronchography (or cough medicines), allergic alveolitis in pituitary-snuff takers, and the congestive atelectasis which can follow the prolonged administration of oxygen.

1 Samter, M., and Beers, R. F., Annals of Internal Medicine, 1968, 68, 975

2 Ford, R. M., American Review of the Respiratory Diseases, 1966, 93, 797

Nicklaus, T. M., and Snyder, A. B., Archives of Internal Medicine, 1968 $121,151$.

Fiegenberg, D. S., Weiss,
Medicine, 1967, 120,85 .

5 Jones, G. R., and Malone, D. N. S., Thorax, 1972, 27, 713.
' Davies, P. D. B., British fournal of Diseases of the Chest, 1969, 63, 57.

7 Heard, B. E., and Cooke, R. A., Thorax, 1968, 23, 187. 